\title{
Effect of Strength Mis-Match on Fracture Mechanical Behavior of HAZ-Notched Weld Joint*
}

\author{
By Fumiyoshi MINAMI**, Masao TOYODA**, Christian THAUlOW*** and Mons HAUGE***
}

\begin{abstract}
Strength mis-matching between the base and weld metals exerts a marked influence on the deformation behavior as well as on the fracture resistance of the weld $H A Z$. HAZnotched CTOD test results for high strength steel welds were discussed with attention to mis-matching effect. Stress fields in the HAZ were addressed by $3 D$ FEM with a model having a notch at the HAZ/weld metal boundary. Strength overmatching of the weld metal brings about different effects depending on the toughness level of the HAZ. In the case of the HAZ with moderate toughness, strength overmatching results in crack path deviation toward a softer material due to asymmetrical plastic deformation. On the other hand, for the embrittled HAZ, the overmatch condition lowers the critical CTOD value of the HAZ. This is attributed to elevation of the local stress in the HAZ by constraint effect of the overmatched weld metal. The geometry of the test specimen also affects the degree of crack tip constraint. The deep notch bend specimen produces the largest geometrical constraint. The fracture resistance of the weld $H A Z$ is controlled by the combined effects of strength mis-matching and the specimen geometry. The geometrical constraint in the deep notch bend specimen was more significant than the constraint by 25\% strength overmatching in the tension specimen.
\end{abstract}

Key Words: Strength mis-matching, Constraint effect, Fracture toughness, Weld HAZ, CTOD test, 3D FEM, Crack path deviation, Local approach

\section{Introduction}

Fracture mechanics tests on the heat affected zone (HAZ) of welded joints are increasingly conducted for weldments of high strength steels where the structural integrity against the brittle fracture is of the greatest concern. The purpose of the test is to detect potential local brittle zones (LBZ) in welds and to evaluate the fracture resistance of the $\mathrm{HAZ}$ including the $\mathrm{LBZ}$. However, the HAZ-notched test imposes complex problems on the evaluation of the test results. The embrittled region in the HAZ is not large enough to be sampled fully by the crack tip of the test specimen. The crack tip intersects several microstructures along the crack front and sometimes fails to hit the region of interest. A more complicate nature is inhomogeneity in mechanical properties in welds. It is known that strength mis-matching between the base and weld metals exerts a large influence on the deformation behavior and the fracture resistance of the HAZ. Conventional fracture mechanics parameters are not always applicable ${ }^{1,2)}$ in the case that strength mis-matching yields asymmetrical crack opening. It has recently been demonstrated ${ }^{3-6)}$ that strength overmatching of the weld metal decreases the cleavage resistance of the HAZ. This is due to the elevation of the local stress in the HAZ by the constraint effect of the overmatched weld metal ${ }^{3,4,7)}$.

Present paper studies the effect of strength mis-matching, especially the effect of strength overmatching, on CTOD test results of the weld $\mathrm{HAZ}$ of high strength steels. The CTOD test results were analyzed with attention to the microstructure at cleavage fracture initiation and the path of ductile crack growth. The crack tip stress fields in the $\mathrm{HAZ}$ region were addressed by three-dimensional FEM with a model having a notch at the boundary between the HAZ and the weld metal. A greater concern was laid on the competition between the geometrical constraint and the constraint induced by strength mismatching. The intensity of the crack tip stress fields in the HAZ was evaluated on the basis of

* Received: 24 January 1994

** Member, Osaka University

*** SINTEF Production Engineering/NTH, Norway 
the local approach for the three-point bend specimens with different notch depth and a center notched panel subjected to tension.

\section{Fracture Properties of HAZ-Notched Welds}

\subsection{CTOD Test on Multipass Weld HAZ}

CTOD tests were carried out ${ }^{8)}$ on the multilayered weld HAZ of high strength steels, steel $\mathrm{B}$ and steel $\mathrm{C}$, for offshore structural use. The steel $B$ is $30 \mathrm{~mm}$ thick and has the yield strength of $467 \mathrm{MPa}$. The steel $\mathrm{C}$ is $50 \mathrm{~mm}$ thick and provides higher yield strength $496 \mathrm{MPa}$. Kgroove welds were made by SAW with heat inputs of $Q=3,5 \mathrm{MJ} / \mathrm{m}$ and by FCAW with $Q=$ $1.5 \mathrm{MJ} / \mathrm{m}$. Table 1 gives the chemical composition and mechanical properties of the base steels and weld metals. Some welded joints are recognized as slightly overmatched. Dimensions of CTOD specimens were $B$ (thickness) $=30 \mathrm{~mm}, W$ (width) $=60 \mathrm{~mm}$ and $a$ (notch length) $=30 \mathrm{~mm}$. CTOD specimens of steel $\mathrm{C}$ welds were extracted from the middle of the joint thickness. The notch was of through-thickness type and located along the straight fusion line of $\mathrm{K}$-groove welds. Fatigue precrack was introduced at the tip of the machine notch after local precompression treatment to relax the welding residual stress.

The CTOD tests were conducted at $-50^{\circ} \mathrm{C}$ in the ductile to brittle transition temperature range. Figure 1 shows the test results obtained. Notations $\delta_{\mathrm{c}}, \delta_{\mathrm{u}}$ and $\delta_{\mathrm{m}}$ follow the British standard BS7448 ${ }^{\circ}$. Critical CTOD values were arranged with the location of the fatigue precrack in

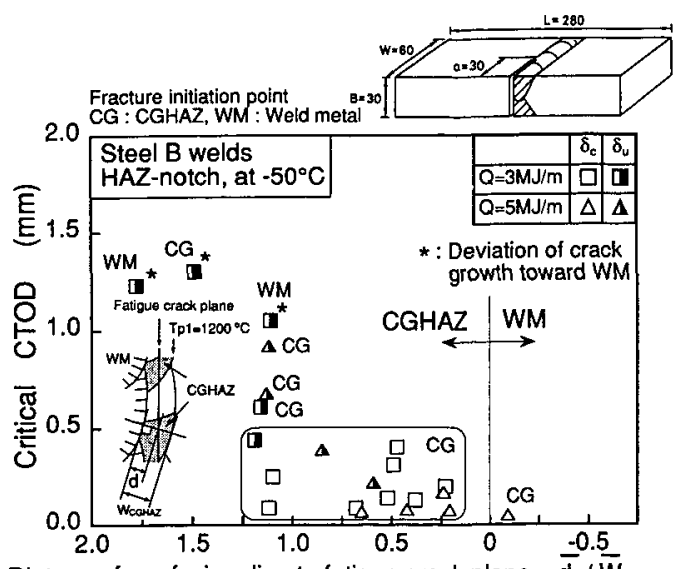

Distance from fusion line to fatigue crack plane, $\bar{d} / \bar{W}_{\text {CGHAZ }}$

(a) Steel B welds with heat inputs of 3 and $5 \mathrm{MJ} / \mathrm{m}$

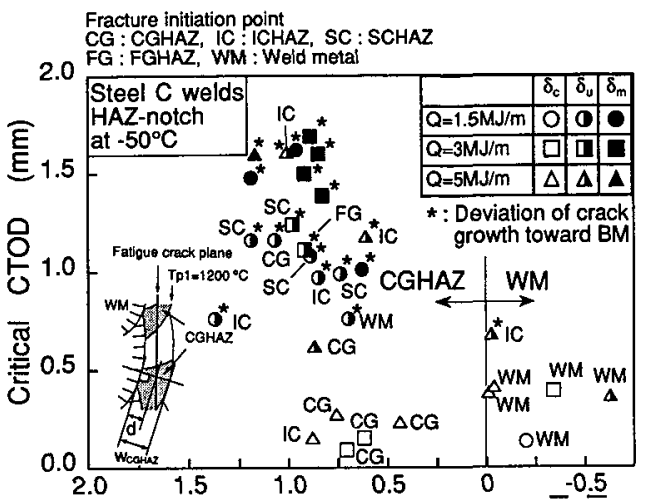

Distance from fusion line to fatigue crack plane, $\bar{d} / \bar{W}_{\text {CGHAZ }}$

(b) Steel $C$ welds with heat inputs of $1.5,3$ and $5 \mathrm{MJ} / \mathrm{m}$

Fig. 1 Relationship between critical CTOD values and crack tip location in welds of HAZ-notched CTOD specimens.

Table 1 Chemical composition and mechanical properties of high strength steels and weld metals.

\begin{tabular}{|c|c|c|c|c|c|c|c|c|c|c|c|c|c|c|c|}
\hline & \multicolumn{13}{|c|}{ Chemical composition (mass \%) } \\
\hline & & & $\mathrm{c}$ & Si & Mn & $P$ & $s$ & $\mathrm{Cu}$ & $\mathrm{Gr}$ & $\mathrm{Ni}$ & Mo & $\mathrm{Nb}$ & Al & $\pi$ & B \\
\hline \multirow{3}{*}{$\begin{array}{c}\text { Steel } \\
\text { B } \\
\text { welds }\end{array}$} & \multicolumn{2}{|c|}{ BM } & 0.07 & 0.23 & 1.51 & 0.007 & $<0.001$ & 0.30 & 0.03 & 0.48 & 0.01 & 0.010 & 0.037 & 0.015 & - \\
\hline & \multirow[b]{2}{*}{ WM } & $Q=3.0$ & 0.07 & 0.18 & 1.47 & 0.010 & 0.005 & 0.13 & 0.04 & 0.10 & 0.21 & Tr. & 0.008 & 0.007 & 0.0007 \\
\hline & & $Q=5.0$ & 0.08 & 0.24 & 1.52 & 0.007 & 0.003 & 0.31 & 0.04 & 0.48 & 0.01 & 0.010 & 0.036 & 0.015 & 0.0005 \\
\hline \multirow{4}{*}{$\begin{array}{c}\text { Steel } \\
\text { C } \\
\text { welds }\end{array}$} & \multicolumn{2}{|c|}{$\overline{\mathrm{BM}}$} & 0.09 & 0.25 & 1.52 & 0.003 & 0.002 & 0.31 & 0.04 & 0.71 & 0.01 & 0.009 & 0.038 & 0.010 & 0.000 \\
\hline & \multirow{3}{*}{ WM } & $Q=1: 5$ & 0.04 & 0.32 & 1.36 & 0.014 & 0.009 & 0.02 & 0.02 & 1.53 & 0.01 & 0.011 & 0.004 & 0.038 & 0.003 \\
\hline & & $Q=3.0$ & 0.08 & 0.23 & 1.40 & 0.011 & 0.005 & 0.12 & 0.04 & 0.14 & 0.22 & Tr. & 0.008 & 0.006 & 0.000 \\
\hline & & $Q=5.0$ & 0.0 & 0.18 & 1.54 & 0.011 & 0.005 & 0.14 & 0.04 & 0.18 & 0.20 & Tr. & 0.009 & 0.005 & 0.00 \\
\hline
\end{tabular}

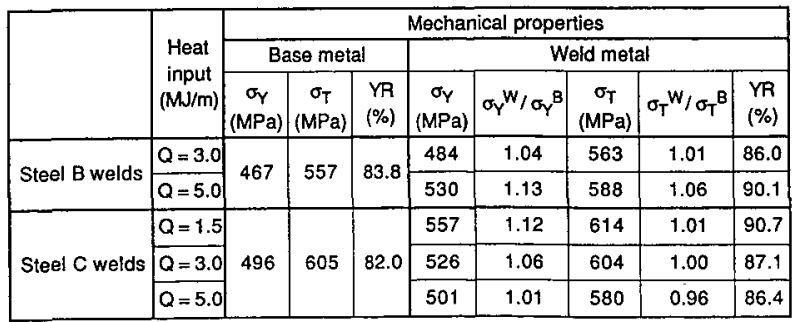

$\sigma_{Y}$ : Yield stress, $\sigma_{T}$ : Tensile strength, YR : Yield to tensile ratio $\left(=\sigma_{Y} / \sigma_{T}\right)$ 
welds. The $\overline{\mathrm{d}} / \overline{\mathrm{W}}_{\mathrm{CGHAZ}}$ denotes the average distance from the fusion line to the fatigue precrack plane normalized by the width of the coarse grain HAZ (CGHAZ). The distance $\overline{\mathrm{d}}$ and the width $\bar{W}_{\text {CGHAZ }}$ were measured in the light of sectioning ${ }^{10)}$ results. In this paper, the CGHAZ was defined as the $\mathrm{HAZ}$ region where the peak temperature of the weld thermal cycle exceeded $1200^{\circ} \mathrm{C}$, as given in Table 2. The peak temperature was calculated by a conventional two-dimensional heat conduction analysis ${ }^{11}$ with an assumption that the temperature at the boundary of Nital-etched HAZ was $900^{\circ} \mathrm{C}$. Critical CTOD values for steel $\mathrm{B}$ welds decrease with the crack tip approaching to the fusion line. In particular, the specimen with a crack tip in the CGHAZ $\left(0<\overline{\mathrm{d}} / \overline{\mathrm{W}}_{\text {CGHAZ }}<1\right)$ gives a small critical CTOD value. On the other hand, steel $\mathrm{C}$ welds have a considerable large scatter in critical CTOD values, even if the crack tip hits the CGHAZ.

\subsection{Constraint Effect vs. Crack Path Deviation Effect}

Fracture behavior was investigated with rela-

Table 2 Classification of HAZ microstructure of multipass welds by peak temperature of weld thermal cycle.

\begin{tabular}{|c|c|c|}
\hline $\begin{array}{c}\text { Peak temperature by } \\
\text { first cycle }\end{array}$ & $\begin{array}{c}\text { Peak temperature by } \\
\text { subsequent cycles }\end{array}$ & HAZ-microstructure \\
\hline \multirow{4}{*}{$\begin{array}{c}\text { Melting point } \sim 1200^{\circ} \mathrm{C} \\
\text { (CGHAZ) }\end{array}$} & \begin{tabular}{c} 
Melting point $\sim 1200^{\circ} \mathrm{C}$ \\
\cline { 2 - 3 }
\end{tabular} & UACGHAZ \\
\cline { 2 - 3 } & $7200 \sim 850^{\circ} \mathrm{C}$ & FGHAZ \\
\cline { 2 - 3 } & $750 \sim 450^{\circ} \mathrm{C}$ & ICCGHAZ \\
\hline \multirow{3}{*}{$\begin{array}{c}1200 \sim 850^{\circ} \mathrm{C} \\
\text { (FGHAZ) }\end{array}$} & Melting point $\sim 1200^{\circ} \mathrm{C}$ & SCCGHAZ \\
\cline { 2 - 3 } & $1200 \sim 850^{\circ} \mathrm{C}$ & UACGHAZ \\
\cline { 2 - 3 } & $850 \sim 750^{\circ} \mathrm{C}$ & FGHAZ \\
\hline \multirow{2}{*}{$\begin{array}{c}850 \sim 750^{\circ} \mathrm{C} \\
\text { (ICHAZ) }\end{array}$} & $750 \sim$ & ICHAZ \\
\cline { 2 - 4 } & Melting point $\sim 1200^{\circ} \mathrm{C}$ & UACGHAZ \\
\cline { 2 - 3 } & $1200 \sim 850^{\circ} \mathrm{C}$ & FGHAZ \\
\hline
\end{tabular}

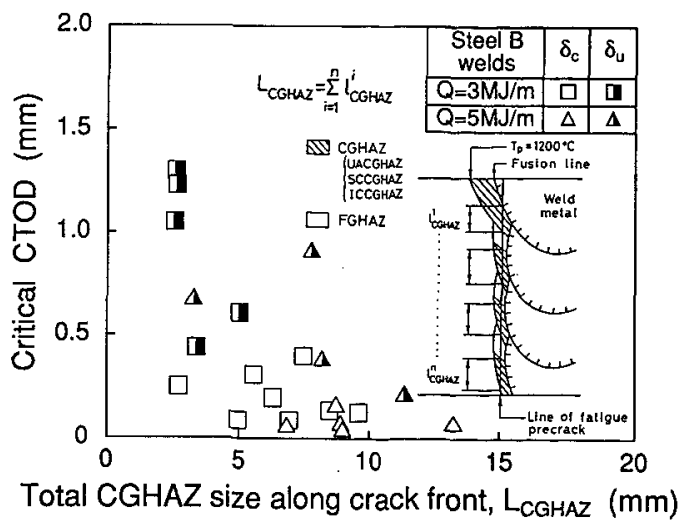

Fig. 2 Relationship between critical CTOD value of HAZ-notched specimen and total size of CGHAZ along crack front. tion to the microstructure along the crack front. In steel B welds, cleavage fracture was initiated from the CGHAZ in the majority of specimens, as shown in Fig. 1(a). Namely the CGHAZ controls the fracture initiation in the multilayered $\mathrm{HAZ}$ of steel $\mathrm{B}$ welds. Figure 2 presents the relationship between the critical CTOD value and the total size of the CGHAZ, $\mathrm{L}_{\mathrm{CGHAZ}}$, along the crack front. It is understood from Fig. 2 and Fig. 1(a) that the crack tip closer to the fusion line hit a larger amount of the CGHAZ, which resulted in a lower critical CTOD value.

On the other hand, for steel $C$ welds (Fig. 1(b)), very few specimens showed brittle fracture from the CGHAZ. In most cases, apparent deviation of ductile crack from the fatigue crack plane was observed. These specimens were marked with $*$ in Fig. 1(b). Figure 3 shows an example of crack path deviation. After curved growth of the ductile crack the unstable fracture occurred at the subcritical HAZ apart from the fatigue crack tip, although the fatigue crack tip hit the CGHAZ. The crack path was directed to the base metal which was softer than the weld metal. Figure 4 exhibits the fraction of crack growth deviation as a function of the yield strength ratio $(\mathrm{Sr})_{\mathrm{Y}}=\sigma_{\mathrm{Y}}^{\mathrm{W}}$ / $\sigma_{\mathrm{Y}}^{\mathrm{B}}$ between the weld and base metals. The specimens with a notch tip in $0<\overline{\mathrm{d}} / \overline{\mathrm{W}}_{\mathrm{CGHAZ}}<1$ were employed. The crack growth deviation is encouraged with increasing the yield strength ratio $(\mathrm{Sr})_{\mathrm{Y}}$. It is pointed out that the critical CTOD values larger than $0.7 \mathrm{~mm}$ were accompanied with crack path deviation. These test results do not present the actual toughness of the CGHAZ, even if the crack tip hit the CGHAZ.

There was no significant difference in the

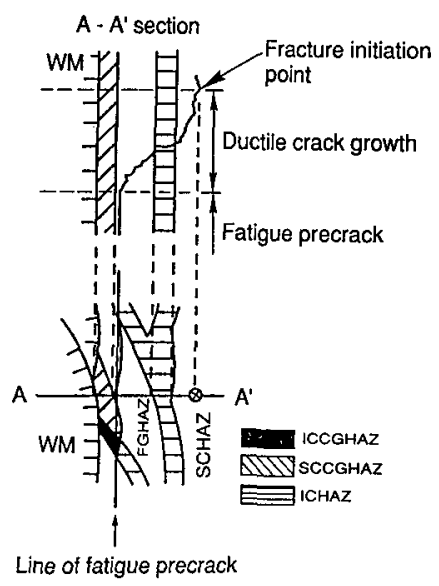

Fig. 3 Observation of crack path deviation from CGHAZ (Steel C welds with heat input $3 \mathrm{MJ} / \mathrm{m}, \delta_{\mathrm{u}}=1.24 \mathrm{~mm}$ ). 


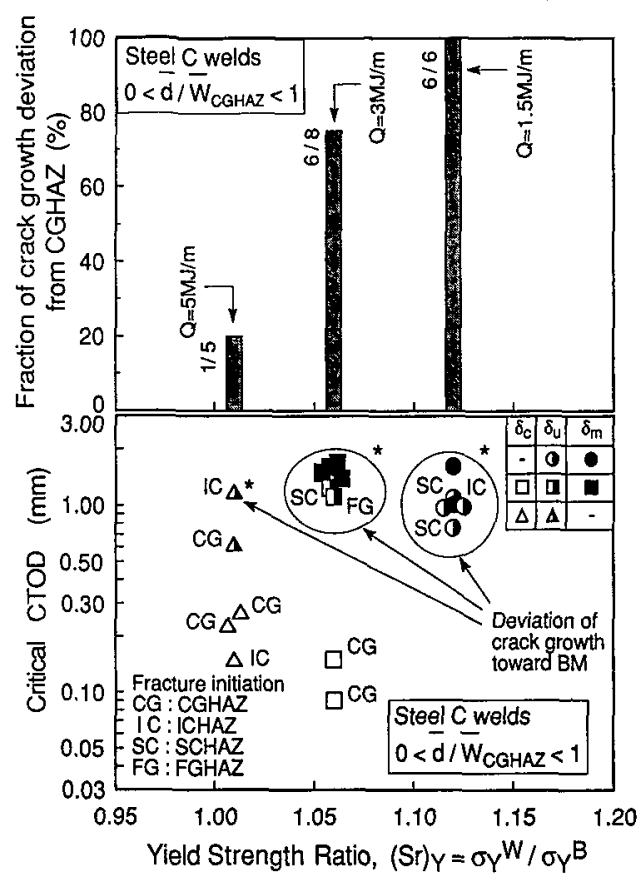

Fig. 4 Influence of yield strength ratio between weld metal and base metal on fracture behavior of HAZ-notched CTOD specimen (Steel $C$ welds).

degree of strength overmatching between steel B welds and steel $\mathrm{C}$ welds (see Table 1 ). Nevertheless the CTOD test on their weld HAZ gave inconsistent results: All steel $B$ welds with the strength ratio $(\mathrm{Sr})_{\mathrm{Y}}=1.13$ presented brittle fracture at a small critical CTOD value (Fig. 1(a)), provided that the crack tip was located in the CGHAZ $\left(0<\overline{\mathrm{d}} / \overline{\mathrm{W}}_{\mathrm{CGHAZ}}<1\right)$. On the other hand, all steel $\mathrm{C}$ welds with $(\mathrm{Sr})_{\mathrm{Y}}=1.12$ showed ductile crack path deviation even if the crack tip hit the CGHAZ (Fig. 1(b), Fig. 4).

In steel $B$ welds, the overmatched weld metal promoted the fracture initiation in the CGHAZ. This is explained in terms of the constraint effect of the overmatched weld metal ${ }^{3,4,7)}$. The plastic constraint elevates the local stress in the CGHAZ, which makes it easy for the material to reach the fracture condition. On the other hand, in the case of steel $\mathrm{C}$ welds, the overmatch condition resulted in crack path deviation toward the softer material. It is expected that the plastic strain was accumulated preferably to a larger extent in the softer material side, before the critical condition for brittle fracture was attained in the CGHAZ. Which effect is more dominant, constraint effect or crack path deviation effect, depends on the toughness level of the CGHAZ, as summarized in Fig. 5.

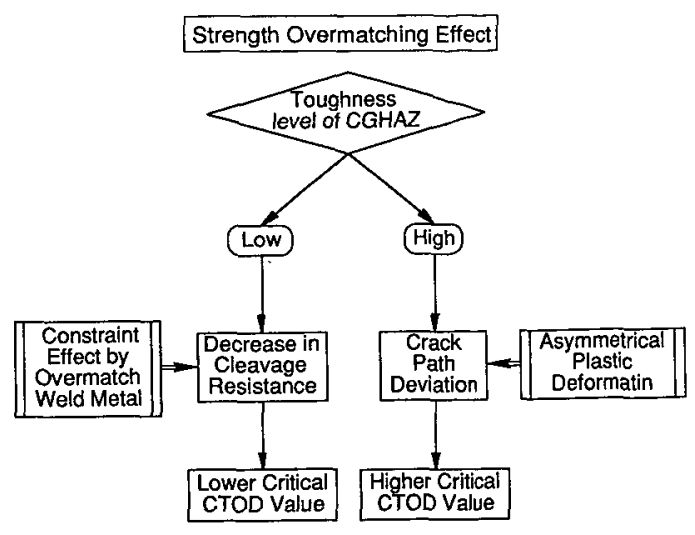

Fig. 5 Effect of strength overmatching on fracture property of $\mathrm{HAZ}$-notched specimen.

\section{Influence of Strength Mis-Matching on Fracture Resistance of Weld $\mathrm{HAZ}$}

\subsection{Welded Joints with Strength Mis-Matching}

As indicated above, the overmatch condition brings about undesirable results in the case of low toughness HAZ. Further investigation has been done on the strength mis-matching effect on fracture resistance of the weld HAZ. HAZ-notched CTOD test results of structural steel welds were examined. Table 3 gives the chemical composition and mechanical properties of the base steels and weld metals. Basic properties of these welded joints are:

- TMCP high strength steel welds

The base steel is a $50 \mathrm{~mm}$ thick TMCP steel with the yield strength $440 \mathrm{MPa}$. Evenmatched and overmatched weld joints were made with the same heat input of $3 \mathrm{MJ} / \mathrm{m}$ by SAW with $\mathrm{K}-$ groove. The yield strength ratios $(\mathrm{Sr})_{\mathrm{Y}}=\sigma_{\mathrm{Y}}^{\mathrm{W}} / \sigma_{\mathrm{Y}}^{\mathrm{B}}$ were 1.09 and 1.32 for the evenmatched joint and the overmatched joint, respectively. Full thickness CTOD specimens were extracted with a through-thickness notch along the straight fusion line. Figure $6(\mathrm{a})$ shows the specimen geometry. CTOD tests were conducted at $-50^{\circ} \mathrm{C}$.

- Mild steel welds ${ }^{3)}$

Overmatched weld joints with different mismatching levels, $(\mathrm{Sr})_{\mathrm{Y}}=1.53$ and 2.49 , were made for a $30 \mathrm{~mm}$ thick mild steel. The yield strength of the base steel was $305 \mathrm{MPa}$. Welding was conducted by SAW with K-groove under a heat input of $4.2 \mathrm{MJ} / \mathrm{m}$. Two types of CTOD specimen were taken, as shown in Fig. 6(b). P-type specimen had a notch along the straight fusion line. Another one, L-type, had a notch perpendicular to welds. In both specimens the notch tip was located in the HAZ about $1.5 \mathrm{~mm}$ from the fusion 
Table 3 Chemical composition and mechanical properties of base steels and weld metals.

\begin{tabular}{|c|c|c|c|c|c|c|c|c|c|c|c|c|c|c|c|}
\hline & \multicolumn{13}{|c|}{ Chemical composition (mass \%) } \\
\hline & & & $\mathrm{C}$ & $\mathrm{Si}$ & $\mathrm{Mn}$ & $\vec{P}$ & $\mathbf{S}$ & $\mathrm{Cu}$ & $\mathrm{Cr}$ & $\mathrm{Ni}$ & Mo & $\mathrm{Nb}$ & Al & $\pi$ & B \\
\hline \multirow{3}{*}{$\begin{array}{c}\text { TMCP } \\
\text { ste日l } \\
\text { welds }\end{array}$} & \multicolumn{2}{|r|}{$\overline{\mathrm{BM}}$} & 0.08 & 0.15 & 1.56 & 0.005 & 0.001 & 0.24 & 0.02 & 0.23 & - & 0.012 & 0.028 & 0.009 & 0.0001 \\
\hline & $\mathrm{WM}$ & Even & 0.09 & 0.23 & 1.55 & 0.013 & 0.006 & 0.11 & 0.01 & 0.04 & $<0.01$ & $<0.003$ & 0.004 & 0.018 & 0.004 \\
\hline & WM & Over & 0.07 & 0.19 & 1.45 & 0.007 & 0.003 & 0.12 & 0.01 & 1.41 & 0.12 & 0.005 & 0.015 & 0.006 & 0.009 \\
\hline \multirow{3}{*}{$\begin{array}{c}\text { Mild } \\
\text { steel } \\
\text { welds }\end{array}$} & \multicolumn{2}{|c|}{$\mathrm{BM}$} & 0.08 & 0.30 & 1.45 & 0.006 & 0.0006 & - & - & 0.02 & - & - & - & 0.005 & - \\
\hline & \multicolumn{2}{|c|}{ WM (Joint I) } & 0.08 & 0.46 & 2.05 & 0.011 & 0.0013 & - & - & 0.09 & - & - & - & 0.003 & - \\
\hline & & $\begin{array}{c}\text { Over } \\
\text { (Joint II) }\end{array}$ & 0.09 & 0.20 & 1.50 & 0.015 & 0.0058 & - & - & 0.02 & - & - & - & 0.013 & - \\
\hline \multirow{3}{*}{$\begin{array}{c}\text { HT780 } \\
\text { steel } \\
\text { welds }\end{array}$} & \multicolumn{2}{|r|}{$\mathrm{BM}$} & 0.12 & 0.27 & 0.93 & 0.009 & 0.003 & 0.25 & 0.50 & 0.99 & 0.25 & - & - & - & 0.0015 \\
\hline & \multirow[b]{2}{*}{ WM- } & Even & 0.07 & 0.35 & 1.82 & - & - & - & 0.96 & 232 & 0.42 & - & - & - & - \\
\hline & & Under & 0.08 & 0.08 & 0.44 & 0.013 & 0.010 & 0.11 & 0.08 & 0.16 & 0.05 & - & - & - & - \\
\hline \multirow{4}{*}{$\begin{array}{c}\text { StE } \\
460 \\
\text { steel } \\
\text { welds }\end{array}$} & \multicolumn{2}{|r|}{$\mathrm{BM}$} & 0.17 & 0.46 & 1,49 & 0.020 & 0.003 & 0.17 & - & 0.44 & - & 0.03 & 0.040 & - & - \\
\hline & \multirow{3}{*}{ WM } & Even & 0.14 & 0.41 & 1.50 & 0.012 & 0.005 & - & 0.01 & 0.28 & - & - & 0.003 & - & - \\
\hline & & Under & 0.10 & 0.34 & 0.94 & 0.017 & 0.001 & - & 9.13 & 26.9 & - & - & 0.044 & - & - \\
\hline & & Over & 0.11 & 0.37 & 1.24 & 0.015 & 0.001 & $=$ & 4.19 & 1.91 & - & - & 0.012 & - & - \\
\hline
\end{tabular}

\begin{tabular}{|c|c|c|c|c|c|c|c|c|c|c|}
\hline & \multirow{3}{*}{$\begin{array}{c}\text { Heat } \\
\text { input } \\
(\mathrm{MJ} / \mathrm{m})\end{array}$} & \multicolumn{8}{|c|}{ Mechanical properties } \\
\hline & & & \multicolumn{3}{|c|}{ Base metal } & \multicolumn{5}{|c|}{ Weld metal } \\
\hline & & & $\begin{array}{c}\sigma_{Y} \\
(\mathrm{MPa})\end{array}$ & $\begin{array}{c}\sigma_{\mathrm{T}} \\
(\mathrm{MPa})\end{array}$ & $\begin{array}{r}\mathrm{YR} \\
(\%)\end{array}$ & $\begin{array}{c}\sigma_{Y} \\
(M P a)\end{array}$ & $\sigma_{\gamma}{ }^{W} / \sigma_{\gamma}{ }^{B}$ & $\begin{array}{c}\sigma_{\top} \\
(\mathrm{MPa})\end{array}$ & $\sigma_{T}{ }^{w / \sigma_{T}}{ }^{\mathrm{B}}$ & $\begin{array}{c}\text { YR } \\
(\%)\end{array}$ \\
\hline \multirow{2}{*}{$\begin{array}{l}\text { TMCP } \\
\text { steel } \\
\text { welds }\end{array}$} & Even & \multirow{2}{*}{$Q=3.0$} & \multirow{2}{*}{440} & \multirow{2}{*}{549} & \multirow{2}{*}{80.1} & 481 & 1.09 & 563 & 1.03 & 85.4 \\
\hline & Over & & & & & 581 & 1.32 & 647 & 1.18 & 89.8 \\
\hline \multirow{2}{*}{$\begin{array}{c}\text { Mild } \\
\text { steel } \\
\text { welds }\end{array}$} & $\begin{array}{c}\text { Over } \\
\text { (Joint I) }\end{array}$ & \multirow{2}{*}{$Q=4.2$} & \multirow[b]{2}{*}{305} & \multirow[b]{2}{*}{438} & \multirow[b]{2}{*}{69.6} & 758 & 2.49 & 861 & 1.97 & 88.0 \\
\hline & $\begin{array}{c}\text { Over } \\
\text { (Joint }\end{array}$ & & & & & 468 & 1.53 & 573 & 1.31 & 81.7 \\
\hline \multirow{2}{*}{$\begin{array}{c}\text { HT780 } \\
\text { sleel } \\
\text { welds }\end{array}$} & Even & \multirow{2}{*}{$Q=3.6$} & \multirow{2}{*}{789} & \multirow{2}{*}{845} & \multirow{2}{*}{93.4} & 711 & 0.90 & 929 & 1.10 & 76.5 \\
\hline & Under & & & & & 336 & 0.43 & 422 & 0.50 & 79.6 \\
\hline \multirow{3}{*}{$\begin{array}{c}\text { StE } \\
460 \\
\text { steel } \\
\text { welds }\end{array}$} & Even & \multirow{3}{*}{$Q=2.9$} & \multirow{3}{*}{458} & \multirow{3}{*}{625} & \multirow{3}{*}{73.3} & 620 & 1.35 & 770 & 1.23 & 80.5 \\
\hline & Under & & & & & 248 & 0.54 & 540 & 0.86 & 45.9 \\
\hline & Over & & & & & 964 & 2.10 & 1230 & $t .97$ & 78.4 \\
\hline
\end{tabular}

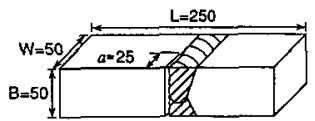

(a) Specimen from $50 \mathrm{~mm}$ thick TMCP steel welds

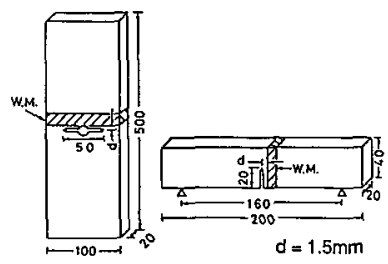

(c) Specimens from $20 \mathrm{~mm}$ thick HT780 steel welds

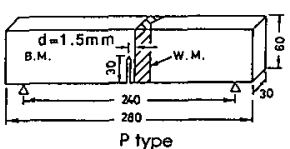

P type

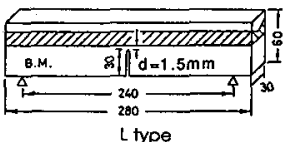

(b) Specimens from $30 \mathrm{~mm}$ thick mild steel welds

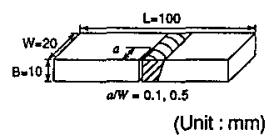

(d) Specimens from $30 \mathrm{~mm}$ thick StE 460 steel welds

Fig. 6 Configurations of CTOD specimens with notch in HAZ.

line. CTOD tests were done at $-120^{\circ} \mathrm{C}$ for $\mathrm{P}$-type specimen and at $-150^{\circ} \mathrm{C}$ for L-type specimen, respectively.

- HT780 steel welds ${ }^{1,2)}$

Evenmatched and undermatched weld joints of a $20 \mathrm{~mm}$ thick high strength steel were made. The yield strength of the base steel was $789 \mathrm{MPa}$.

The strength ratios $(\mathrm{Sr})_{\mathrm{Y}}$ for the evenmatched joint and the undermatched joint were 0.90 and 0.43 , respectively. Welding was conducted by SAW with I-groove under the same heat input of $3.6 \mathrm{MJ} / \mathrm{m}$. The tension specimen and the bend specimen with a through thickness notch in the HAZ were taken, as shown in Fig. 6(c). The distance from the notch tip to the fusion line was about $1.5 \mathrm{~mm}$. Tests were conducted at $-100^{\circ} \mathrm{C}$. - StE 460 steel welds ${ }^{5)}$

A $30 \mathrm{~mm}$ thick C-Mn steel with the yield strength $458 \mathrm{MPa}$ was used. Bead-on-plate welds were produced by SAW under the heat input of $2.9 \mathrm{MJ} / \mathrm{m}$ with three different filler metals ; a low strength austenitic material, a normal strength ferritic material and a high strength martensitic material. The yield strength ratios $(\mathrm{Sr})_{\mathrm{Y}}$ of these welds were $0.54,1.35$ and 2.10 , respectively. HAZ -notched CTOD specimens with notch depth ratios $a / W=0.1$ and 0.5 were employed, see Fig. 6(d). Tests were carried out at room temperature. The CTOD value was measured with $\delta_{5}$ clip gage $^{12)}$ mounted on the specimen's side surface at the original fatigue crack tip over a gage length of $5 \mathrm{~mm}$. 


\subsection{Strength Mis-Matching Effect on Critical CTOD}

Figure 7 summarizes the CTOD results as a function of the yield strength ratio $(\mathrm{Sr})_{\mathrm{Y}}$. The CTOD values for the TMCP steel welds, mild steel welds and HT780 steel welds were calculated in accordance with BS5762 ${ }^{13}$. For the tension specimen the Dugdale model ${ }^{14)}$ was used. It is found in each steel weld that the CTOD results for the weld $\mathrm{HAZ}$ apparently depend on the strength ratio $(\mathrm{Sr})_{\mathrm{Y}}$; a specimen with larger $(\mathrm{Sr})_{\mathrm{Y}}$ gives a smaller critical CTOD value on the average. This tendency is common to all specimen geometries used. Two plausible reasons are considered. 1) Inappropriate evaluation of CTOD : Asymmetrical crack opening caused by mechanical heterogeneity should be taken into account. 2) The constraint effect of the overmatched weld metal on the HAZ toughness.

Figure 8 rearranges the CTOD results by using the local CTOD ${ }^{1,2)}$. The local CTOD in the HAZ was calculated on the basis of FE-analysis. With respect to the TMCP steel welds the critical CTOD values were converted by the weakest link model to those for specimens with a certain CGHAZ size $\mathrm{L}_{\mathrm{CGHAZ}}=10 \mathrm{~mm}$, because the evenmatched specimen and the overmatched specimen had different CGHAZ size along the crack front. Looking at the HT780 steel welds, the critical CTOD values of the undermatched joints evaluated by the local parameter are almost the same as those of the evenmatched joints. In mild steel welds and TMCP steel welds, however, the overmatched joints still give lower critical CTOD values than the evenmatched joints. This is due to the constraint effect of the overmatched weld metal. Figure 9 demonstrates the influence of

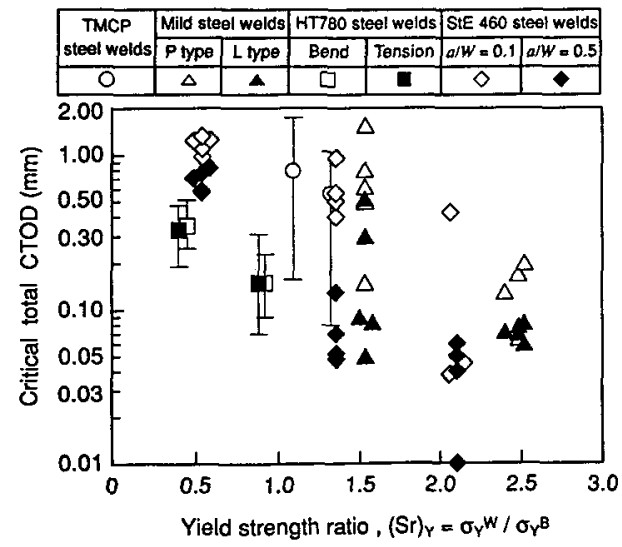

Fig. 7 Effect of yield strength ratio on critical CTOD (total CTOD) of HAZ-notched specimens. strength overmatching on the near-crack tip stress in the HAZ. The CTOD specimens extracted from the TMCP steel welds were analyzed by 3D FEM with a model having a notch at the

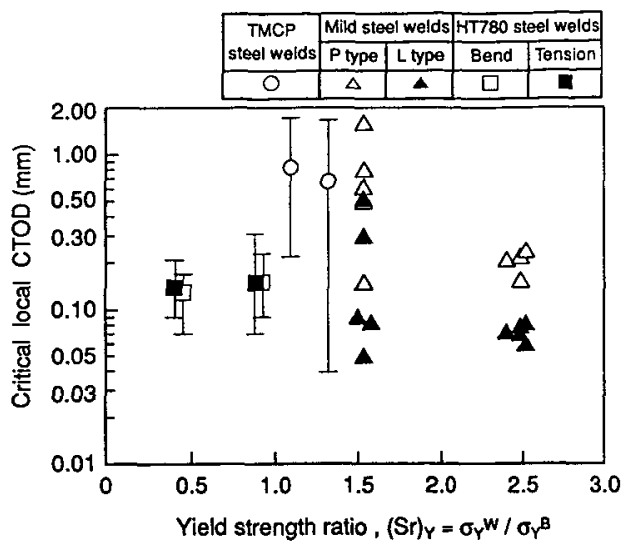

(a) Effect of yield strength ratio on critical local CTOD.

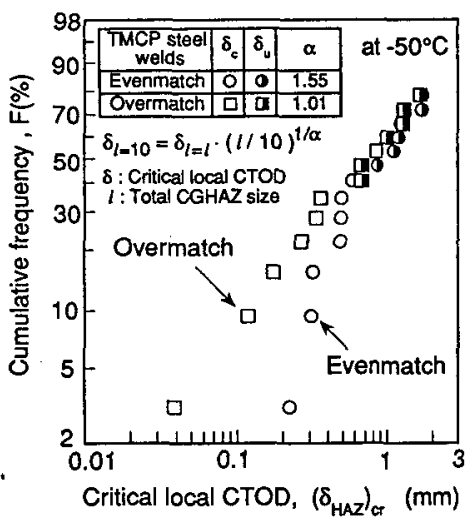

(b) Cumulative distributions of critical local CTOD for evenmatch and overmatch specimens with CGHAZ size $\mathrm{L}_{\mathrm{OGHAZ}}=10 \mathrm{~mm}$ along crack front (TMCP steel welds).

Fig. 8 CTOD test results of HAZ-notched spec. imens evaluated by local CTOD parameter (L type specimen from HT780 steel welds : Total $\mathrm{CTOD}=$ Local CTOD).

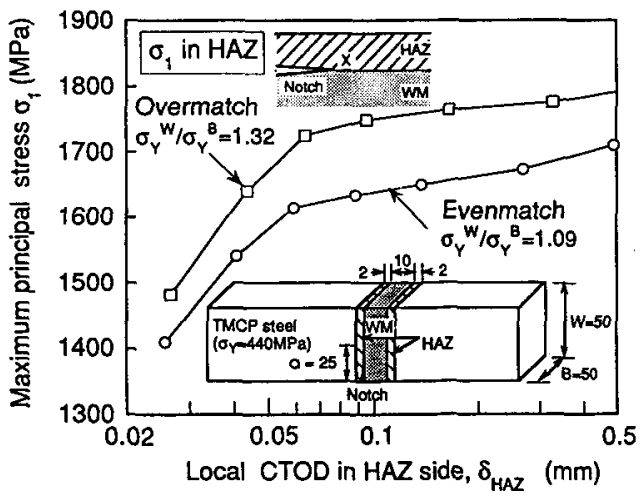

Fig. 9 Influence of strength overmatching on near-crack tip stress in $\mathrm{HAZ}$ analyzed by 3D FEM. 
HAZ/WM boundary. It can be seen that the overmatch condition increases the near-tip stress in the HAZ.

\section{Constraint Effect by Strength Mis- Matching vs. Geometrical Constraint}

\subsection{Finite Element Model}

In view of the importance of constraint effect on the fracture resistance of the weld $H A Z$, this chapter compares the constraint caused by strength mis-matching with the geometrical constraint.

3D FE-analyses were conducted for a center cracked panel (CCP) and single edge-notched bend (SENB) specimens with a shallow notch and a deep notch. Figure 10 illustrates the configuration of the specimens employed. The notch is located at the boundary between the $\mathrm{HAZ}$ and the weld metal. The notch depth ratios, $a / W$, for the SENB specimens are 0.1 and 0.5 , while one for the CCP is 0.5 . Figure 11 shows the stress-strain curves of the base metal, weld metals and the HAZ used in the analysis. The base metal was supposed to be a high strength steel with the yield strength $460 \mathrm{MPa}$. The weld metal has different strength levels; $25 \%$ undermatch, evenmatch and $25 \%$ overmatch against

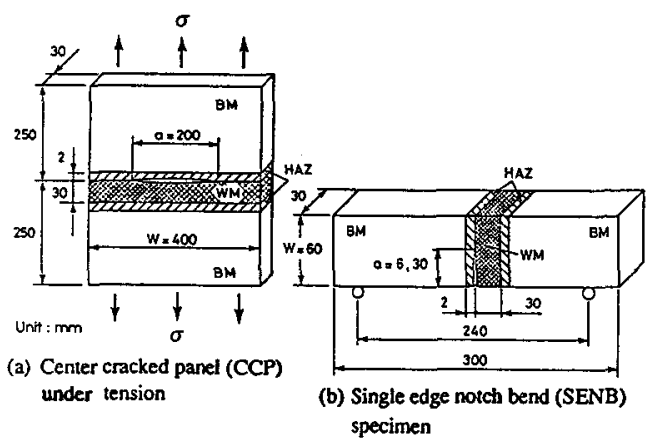

Fig. 10 HAZ-notched specimens used in $\mathrm{FE}$ analysis.

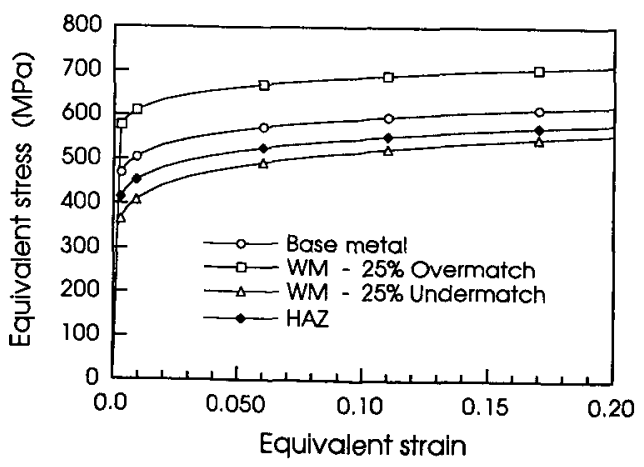

Fig. 11 Stress-strain curves of base steel, HAZ and weld metals used in FE-analysis. the yield strength of the base metal. The HAZ was assumed to be a softened $H A Z$ with the yield strength $400 \mathrm{MPa}$. The $\mathrm{HAZ}$ in the $\mathrm{FE}$-model was a strip of width $2 \mathrm{~mm}$.

The FE-code, NIKE-3D, was used in the analysis. The elements used were 8-node isoparametric elements with 8 Gaussian points. The crack tip was modeled by collapsed elements to simulate crack tip blunting. The edge size of the crack tip elements was $0.1 \mathrm{~mm}$. Because of symmetry, half of the SENB specimens and quarter of the CCP were modeled. The FE-models consisted of 4 layers in the half thickness of the specimen. The layer thicknesses were 1.5 (surface) , 1.5, 4.5 and $7.5 \mathrm{~mm}$ (mid-thickness). The $90^{\circ}$ intercept technique to crack flanks ${ }^{15}$ ) was used to determine the crack tip opening displacement. The local CTOD $\delta_{\mathrm{HAZ}}$ in the HAZ side was adopted.

\subsection{Influence of Specimen Geometry on Crack Tip Stress Fields in HAZ}

Figure 12 shows the distributions of crack opening stress $\sigma_{\mathrm{yy}}$ in the HAZ along the HAZ/ weld metal boundary for the SENB specimen with a deep notch $a / W=0.5$. The stress distribution depends to a large extent on the mismatching condition: Overmatching elevates the near crack-tip stress in the $\mathrm{HAZ}$, while undermatching relaxes it. Stress elevation in the HAZ makes it easy to attain the critical condition for fracture initiation in the HAZ. Figure $13 \mathrm{com}$ pares the influence of strength overmatching on the stress distribution in the HAZ for different specimen geometries. It should be noted that the near-tip stresses for the SENB specimen of $a$ / $W=0.1$ and the CCP under overmatch condition do not exceed the stress level of the evenmatch SENB specimen of $a / W=0.5$.

Strength mis-matching affects the development of a highly stressed region in the HAZ. Figure 14 draws the contours of the maximum principal

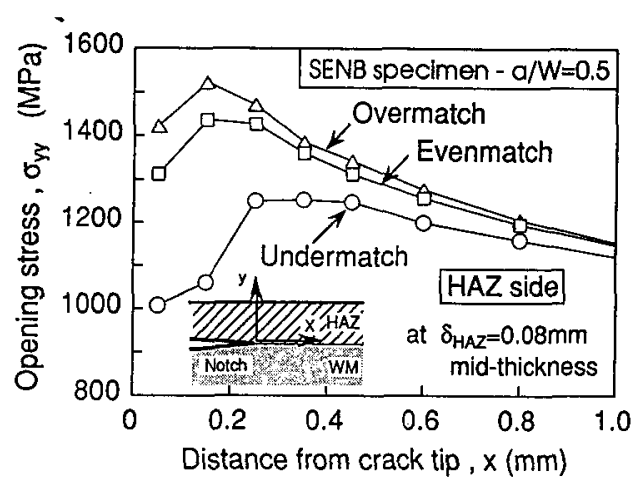

Fig. 12 Distribution of crack opening stress $\sigma_{y y}$ in $\mathrm{HAZ}$ along $\mathrm{HAZ} / \mathrm{WM}$ boundary for SENB specimen with $a / W=0.5$. 


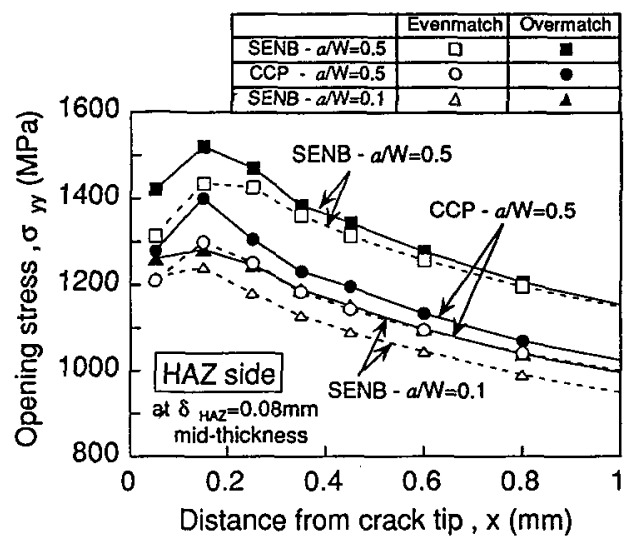

Fig. 13 Influence of strength overmatching on stress distribution in HAZ for SENB specimens and CCP.

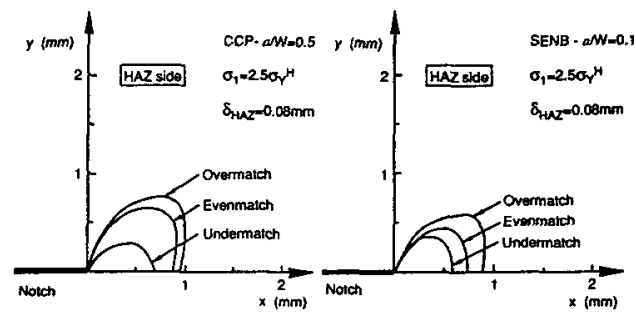

(a) $\mathrm{CCP}$ with $a / W=0.5$

(b) SENB specimen with $a / W=0.1$

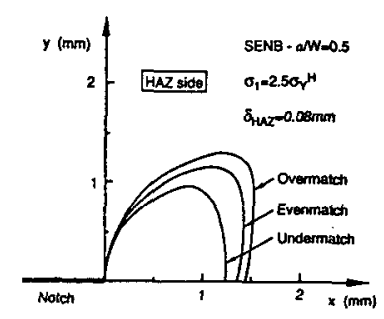

(c) SENB specimen with $a / W=0.5$

Fig. 14 Contours of the maximum principal stress in $\mathrm{HAZ}$ region defined by loci $\sigma_{1}=2.5 \sigma_{\mathrm{Y}}^{\mathrm{H}}$ at local CTOD $\delta_{\mathrm{HAZ}}=0.08 \mathrm{~mm}$, where $\sigma_{\mathrm{Y}}^{\mathrm{H}}$ is yield strength of HAZ.

stress $\sigma_{1}$ in the HAZ, along which the $\sigma_{1}-$ value is 2.5 times the yield strength of the $\mathrm{HAZ}$, for the SENB specimens and the CCP at the same CTOD level. In each specimen geometry, the highly stressed region is expanded by the overmatch condition and reduced by the undermatch condition. The greater concern is the largest contour of $\sigma_{1}$ in the SENB specimen with a deep notch $a /$ $W=0.5$. The $\sigma_{1}$-contours for the SENB specimen of $a / W=0.1$ and the CCP specimen of $a / W=0.5$ are very similar.

\subsection{Local Approach to Fracture Resistance Eval- uation of $H A Z$-Notched Specimen}

A's demonstrated by FE-results, strength mis- matching between the base and weld metals exerts a marked influence on the stress level as well as on the size of activated region in the HAZ. With these properties in mind, the local approach $^{16,17}$ has been applied in the evaluation of fracture resistance of the HAZ-notched specimen.

In the local approach the fracture resistance of the material is evaluated by the Weibull stress $\sigma_{\mathrm{w}}$. Under the condition that brittle fracture originates in the HAZ, the Weibull stress $\sigma_{\mathrm{W}}$ for the HAZ-notched specimen is given by ${ }^{3,7)}$

$$
\sigma_{\mathrm{W}}=\left[\frac{1}{V_{0}} \int_{\mathrm{v}_{\mathrm{f}, \mathrm{HAZ}}}\left[\sigma_{\mathrm{eff}}\right]^{m} d V_{\mathrm{f}, \mathrm{HAZ}}\right]^{1 / m}
$$

where $m$ is the Weibull shape parameter for the $\mathrm{HAZ}, V_{\mathrm{f}, \mathrm{HAZ}}$ is the volume of the fracture process zone in the $\mathrm{HAZ}, \sigma_{\text {eff }}$ is an effective stress in a small volume $d V_{\mathrm{f}, \mathrm{HAZ}}$ in the fracture process zone, and $V_{0}$ is a reference volume defined in the local approach. In this paper the effective stress $\sigma_{\text {eff }}$ was evaluated by ${ }^{18}$

$$
\begin{aligned}
\sigma_{\mathrm{eff}}= & {\left[\frac{1}{2 \pi} \int_{0}^{\pi} \int_{0}^{\pi}\left[\sigma_{\mathrm{n}}^{2}+\frac{4}{(2-\nu)^{2}} \tau^{2}\right]^{m / 2}\right.} \\
& \sin \theta d \theta d \varphi]^{1 / m}
\end{aligned}
$$

with considering the triaxial stress state in the HAZ. The coplanar energy release rate concept ${ }^{19)}$ was used in the derivation of Eq. (2), and the penny-shape microcrack was assumed as a fracture initiation source ${ }^{16,17)}$ in the HAZ. The stresses $\sigma_{\mathrm{n}}$ and $\tau$ are the normal stress and inplane maximum shear stress for the microcrack, respectively. The angles $\theta$ and $\varphi$ define the orientation of the microcrack to the principal stress axes. The increase in the Weibull stress leads to the increase in failure probability for the $\mathrm{HAZ}$. In the calculation of the Weibull stress, $m=20$ was used in the light of literatures ${ }^{16,20-23)}$ and a unit volume was taken as the reference volume $V_{0}$.

Figure 15 shows the influence of strength mismatching on the Weibull stresses $\sigma_{\mathrm{w}}$ of the HAZnotched specimens. As expected from Figs. 12 and 14, the Weibull stress is increased by overmatching and decreased by undermatching in each specimen geometry. It is found, however, that the degree of strength mis-matching effect depends on the specimen geometry. Figure 16 compares the Weibull stresses of the SENB specimens and the CCP at the same CTOD level. The undermatching effect on the Weibull stress is remarkable in the CCP and the deep notch SENB specimen of $a / W=0.5$. The overmatching effect is similar in three specimens. A more significant result is that the SENB specimen of $a / W=0.5$ 


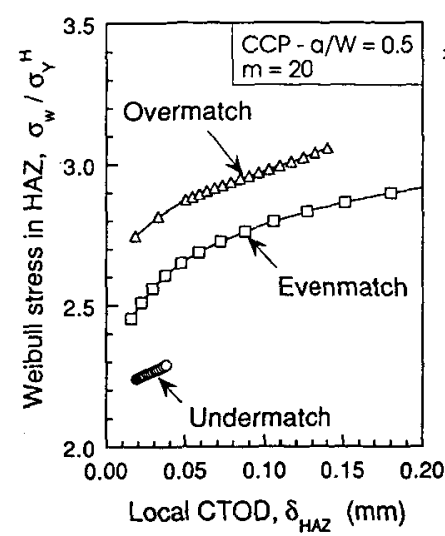

(a) $\mathrm{CCP}$ with $a / W=0.5$

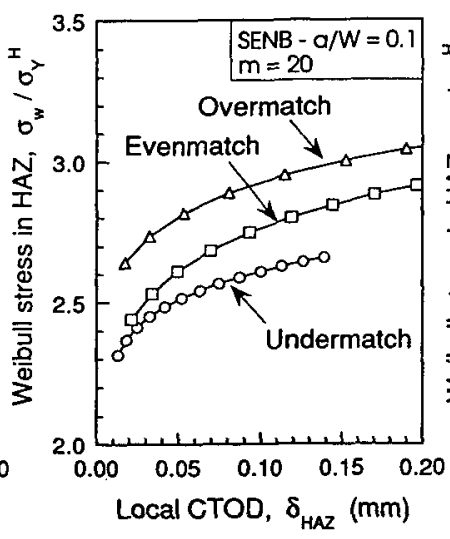

(b) SENB specimen with $a / W=0.1$

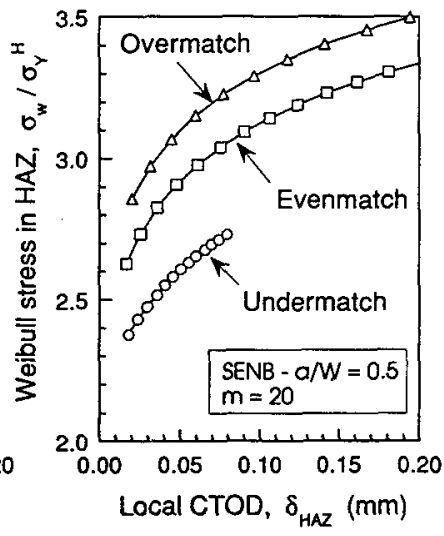

(c) SENB specimen with $a / W=0.5$

Fig. 15 Variation of Weibull stress $\sigma_{w}$ evaluated for HAZ with local CTOD $\delta_{\mathrm{HAZ}}$.

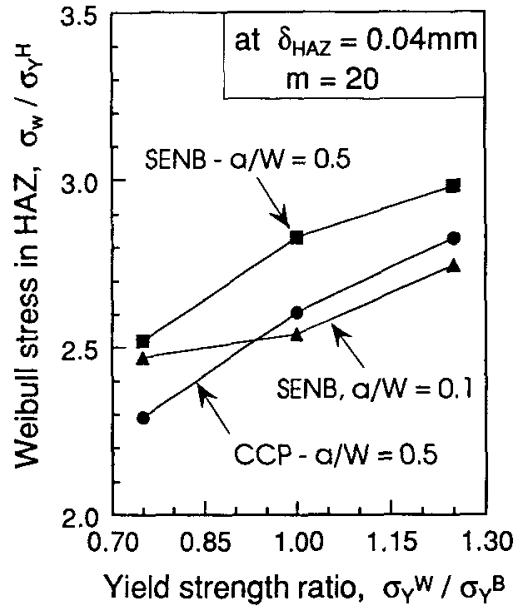

Fig. 16 Influence of specimen geometry and strength mis-matching on Weibull stress of HAZ.

retains the highest Weibull stress. This is due to the geometrical constraint in the deep notch bend specimen $^{24}$, as demonstrated in Figs. 13 and 14. The geometrical constraint seems to be more intense than the constraint caused by $25 \%$ overmatching, because the Weibull stresses of the CCP and the SENB of $a / W=0.1$ in overmatch condition do not exceed the Weibull stress of the evenmatch SENB of $a / W=0.5$.

The FE-results in this paper indicate that the overmatch condition is not beneficial to the weld $\mathrm{HAZ}$ in the case that the HAZ controls the fracture initiation in the welds. Strength balance between the base and weld metals should be considered in the design of welded joints. The procedure for material selection for welds is under progress ${ }^{25,26)}$ with considering the combined effects of strength mis-matching and the specimen geometry.

\section{Concluding Remarks}

Fracture toughness results of CTOD specimens with a notch in the weld HAZ were discussed with attention to the influence of strength mismatching between the base and weld metals. The strength overmatch of the weld metal brought about different effects depending on the toughness level of the CGHAZ. In the case that the CGHAZ had moderate toughness, the overmatch condition resulted in ductile crack path deviation toward a softer material. The resultant CTOD data do not mean the actual toughness of the CGHAZ sampled by the fatigue crack tip. On the other hand, in the case of the embrittled CGHAZ, the overmatch condition promoted fracture initiation in the CGHAZ and lowered the critical CTOD value of the CGHAZ. This was due to constraint effect of the overmatched weld metal. Accordingly, strength overmatching is not always beneficial.

The FE-results presented that the fracture resistance of the HAZ-notched specimen is affected by the specimen geometry. The deep notch bend specimen produced the geometrical constraint to the largest extent. The geometrical constraint in the deep notch bend specimen was more intense than the constraint caused by $25 \%$ strength overmatching for the center notch tension panel and the shallow notch bend specimen.

\section{Acknowledgement}

The present work was conducted as a subtask of the Norway-Japan cooperative research project ( $\mathrm{N}-\mathrm{J}$ project) promoted by Osaka University and SINTEF. Cordial arrangements by the project chairman, Dr. Olaf Andersen in STATOIL, are gratefully acknowledged. The technical discussion and financial supports by the project 
members, the Japanese steelmakers and Norwegian yards, are also highly acknowledged.

\section{References}

1) Satoh, K., Toyoda, M., Minami, F., Arimochi, K., Nakanishi, M. and Satoh, S., A Proposal of Generalized COD Criterion and Its Application to Welds, Quarterly J1. Japan Welding Society, Vol. 2 (1984), 447-454 (in Japanese).

2) Arimochi, K., Nakanishi, M., Toyoda, M. and Satoh, K., Local CTOD Criterion Applied to Fracture Evaluation of Weldments, Proc. Int. Sympo. Storage and Transport of LPG and LNG, Brugges, (1984).

3) Minami, F., Hada, S., Ruggieri, C. and Toyoda, M., Analysis of Strength Mis-Matching of Welds on Fracture Performance of HAZ-Notched Joint, IIW Doc. X-1254-92, Proc. Workshop on Strength Mismatching and Its Control, Tokyo, (1992), 77-86.

4) Thaulow, C., Paauw, A.J., Hauge, M., Toyoda, M. and Minami, F., Fracture Property of HAZ-Notched Weld Joint with Mechanical Mismatching-Part II, Effect of Local Mechanical Mis-Matching on Fracture Initiation in Steel Weldment, Proc. Int. Sympo. Mis-Matching of Welds, ESIS Publication 17 (Edited by Schwalbe, K.-H. and Koçak, M.) (1994), 417-432.

5) Koçak, M., Schwalbe, K.-H., Chen, L. and Griniss, G., Effects of Notch Position and Weld Metal Matching on CTOD of HAZ, Proc. Int. Conf. Weld Failures, London, (1988).

6) Koçak, M., Es-Souni, M., Chen, L. and Schwalbe, K.-H., Microstructure and Weld Metal Matching Effects on Heat Affected Zone Toughness, Proc. 8th Int. Conf. OMAE, The Hauge, Vol. 3 (1989), 623-631.

7) Toyoda, M., Minami, F., Ruggieri, C., Thaulow, C. and Hauge, M. : Fracture Property of HAZ-Notched Weld Joint with Mechanical Mis-Matching-Part I. Analysis of Strength Mis-Matching of Welds on Fracture Initiation Resistance of $\mathrm{HAZ}$-Notched Joint, Mis-Matching of Welds, ESIS Publication 17 (Edited by Schwalbe, K.H. and Koçak, M.) (1994), 399-415.

8) Minami, F., Nakano, Y., Suzuki, S., Shiwaku, T., Moriya, Y., Hagiwara, Y. and Toyoda, M., Fracture Toughness Evaluation of Multipass Weld HAZ with Focus on Mechanical Mis-Matching Effect, Quarterly Jl. Japan Welding Society, Vol. 12 (1994), 568-574.

9) BS7448-Part 1: 1991, Fracture Mechanics Toughness Tests, Method for Determination of $K_{\mathrm{IC}}$, Critical CTOD and Critical $J$ Values of Metallic Materials, British Standard Institution.

10) API RP 2Z: Recommended Practice for Preproduction Qualification for Steel Plates for Offshore Struc. tures (1987).

11) Nakao, Y., Ohshige, H., and Noi, S.: Distribution of Microstructures and Toughness in HAZ of MultiPass Welded High Strength Steel, Proc. 4th Int. Sympo. Japan Welding Society, Osaka, Vol. 2 (1982), 503-508.
12) Hellmann, D. and Schwalbe, K.-H., Geometry and Size Effects on $J-R$ and $\delta-R$ Curves under Plane Stress Conditions, ASTM STP 833, (1984), 577-605.

13) BS5762: 1979 , Methods for Crack Opening Displacement (COD) Testing, British Standard Institution.

14) Bilby, B.A., Cottrell, A.H., Smith, E. and Swinden, K. H. : Plastic Yielding from Sharp Notches, Proc. Roy. Soc. London, Vol. A272 (1964), 1.

15) Tracey, D.M., Finite Element Solutions for CrackTip Behavior in Small-Scale Yielding, Jl. Engineering Materials and Technology, Vol.98 (1976), 146151.

16) Beremin, F.M., A Local Criterion for Cleavage Frac ture of a Nuclear Pressure Vessel Steel, Metallurgical Trans. A, Vol.14A (1983), 2277-2287.

17) Mudry, F., A Local Approach to Cleavage Fracture, Nuclear Engineering Design, Vol. 105 (1987), 65-76.

18) Minami, F., Brükner-Foit, A. and Trolldenier, B., Numerical Procedure for Determining Weibull Parameters Based on The Local Approach, Proc. 8th Biennial European Conference on Fracture-ECF8, Torino, Vol. 1 (1990), 76-81

19) Paris, P.C. and Sih, G.C., Stress Analysis of Cracks, ASTM STP 381, (1965), 30-83.

20) Minami, F., Brükner-Foit, A., Munz, D. and Trolldenier, B., Estimation Procedure for the Weibull Parameters Used in the Local Approach, Int. J1. Fracture, Vol. 54 (1992), 197-210.

21) Bakker, A. and Koers, R.W.J., Prediction of Cleavage Fracture Events in the Brittle-Ductile Transition Region of a Ferritic Steel, European Symposium on Elastic-Plastic Fracture Mechanics, Freiburg, (1989).

22) Miyata, T., Otsuka, A., Otake, T. and Suzuki, Y., Correlation Between Fracture Toughness and Tensile Strength Properties of Steels, J1. Society of Materials Science, Japan, Vol. 39 (1990), 1549-1555 (in Japanese).

23) Ruggieri, C., Minami, F., Toyoda, M., Hagiwara, Y. and Inoue, T., Local Approach to Notch Depth Dependence of CTOD Results, J1. Naval. Archit. Japan, Vol. 171 (1992), 493-499.

24) Minami, F., Ruggieri, C., Toyoda, M., Arimochi, K., Suzuki, S. and Bessyo, K., Significance of Shallow Notch CTOD Test in Fracture Performance Evaluation of Welded Joint, Proc. 12th Int. Conf. OMAE, Glasgow, Vol. 3B (1993), 761-768.

25) Minami, F. and Toyoda. M., Probabilistic Approach to Link Between Design Concept and Toughness Requirement by the Local Approach, IIW Doc. X1300-94, Proc. 2nd Workshop, Constraint Effects on the Structural Performance of Welded Joints, Osaka, (1994), 142-146.

26) Minami, F., Ohata, M., Toyoda, M., Tanaka, T., Arimochi, K., Glover, A.G., North, T.H., Czerniawski, H., Yield Strength Mis-Match Effect on Fracture Performance of Girth welded Joints of Grade 550 Pipeline Steel, Proc. 14th Int. Conf. OMAE, Copenhagen, Vol. 5 (1995), 145-159. 